\title{
State of the art data exchange in agriculture in the EU27 \& Switzerland: survey of the agriXchange project
}

\author{
Frederick Teye ${ }^{1)}$, Henri Hoslter ${ }^{2)}$ and Liisa Pesonen ${ }^{1)}$ \\ ${ }^{1)}$ MTT Agrifood research Finland \\ Plant Production Research \\ Crop Science and Technology \\ Frederick.teye@mtt.fi, liisa.pesonen@mtt.fi \\ ${ }^{2)}$ Wageningen University \& Research centre \\ Livestock Research \\ e-mail:henri.holster@wur.nl
}

\begin{abstract}
Within the agricultural knowledge-based bio-economy, information sharing is an important issue. Information systems for agricultural supply food chain network are not standardized. This reduces efficiency in the exchange of information in agri-business processes. To address these problems, agriXchange, an EU-funded coordination and support action was setup to develop a sustainable network system for common data exchange in the agricultural sector. The overall objectives are to: a) establish a platform on data exchange in agriculture in the EU, b) develop a reference framework for interoperability of data exchange, and c) identify the main challenges for harmonizing data exchange. Analysis of the situation concerning data exchange in agriculture in individual EU member states (including Switzerland) is an integral component of this harmonization support action. In this paper the results of the investigation of the state-of-the art around agricultural data exchange in EU member states is reported.

This research on data exchange and data integration was carried out in $27 \mathrm{EU}$ member states and Switzerland. The investigation employed experts to quantitatively and qualitatively inquire about agricultural data exchange in the EU. A framework was developed to inquire the different integration levels, within as well as between enterprises in agriculture. Based on the analysis of the state of the art, the challenges for future research and trends data exchange in European agriculture were identified.

The results showed that there are substantial differences across the EU in relation to the level of data integration and standardization. Member states can be divided into different groups from; none or hardly any data integration to quite well developed infrastructures such as France, Germany, The Netherlands and Denmark. The most important findings identified were with the aging population of farmers which manifests itself through the lack of adaption and investments in new technology, especially in Southern and Eastern countries. Availability of mobile and broadband infrastructure was a major problem in rural areas for most countries in a quantitative sense, but for ICT developed agricultural countries more of a quality of service problem. Cost of acquiring data exchange capable equipment, data exchange formats, proprietary data formats and complexity in machines was also a major concern. As a recommendation, it was noted that open networks with flexible relationships between network partners will facilitate successful integration of systems. The importance of agricultural data exchange in the EU has broadly been recognized, however all service providers and users need to be convinced about the benefits. Finally, focus should be on putting research information into practice to demonstrate how data harmonization processes can work, however, this should be kept flexible and hence keep the rigidity of (formal) standardization processes minimal in agricultural data harmonization.
\end{abstract}

\section{Keywords:}

agriculture, ICT, information, data exchange, standardisation 


\section{Introduction}

Within the knowledge-based bio-economy, information sharing is an important issue. In agrifood business, this is a complex issue because many aspects and dimensions play a role. Information systems for agriculture lack standardization, which hampers efficient exchange of information (Nikkilä et al., 2010). This issue subsequently leads to inefficient business processes and hampers adaption of new knowledge and technology (Sørensen et al., 2010). The exchange of information at whole chain or network level is poorly organized. Although arable and livestock farming systems have their own specific needs, there are many similarities in the need for an integrated approach. Spatial data increasingly plays an important role in agriculture (Gebbers and Adamchuk, 2010).

CGI (2006) described meaning of information sharing and standardisation with the following words: "Companies must be prepared to share standards-based data free of charge. Sharing information between trading partners will result in an improved information flow and, as a consequence, improved collaboration to better serve the consumer. A resulting collaborative information platform could become the basis for further supply chain solutions". The publication of the Techology Platform (2010) on strategic European research agenda, noted that ICT will play a key role in particular in providing new information management systems and better communication between the different actors in addition to increasing productivity of farming systems. The publication also refers to future ICT for communicating values and providing tools for consumers to enable ethical decision making concerning food.

In order to contribute to a better harmonization of ICT development in European agri-business, the EU-funded project 'agriXchange' was started in 2010. The overall objective of 'agriXchange' is to coordinate and support the setting up of a sustainable network for developing a system for common data exchange in agriculture. This will be achieved by 1) establishing a platform on data exchange in agriculture in the EU, 2) developing a reference framework for interoperability of data exchange and 3 ) identifying the main challenges for harmonizing data exchange.

As a first step in this project, the state-of-the art of ICT and data exchange in agriculture was examined. This paper highlights the set up and results of research carried out into the state-of-the art of ICT and data exchange in agriculture in the EU member states (incl. Switzerland). Additionally, results on specific topics are discussed and general recommendations are defined.

\section{Materials and methods}

The aim of this paper is to obtain an overview of state of the art of current data exchange in general within the EU and specifically within each EU region. Research on data exchange and data integration was carried out in $27 \mathrm{EU}$ member states and Switzerland; in focus groups A to F (Table 1).

Table 1. Responsible consortium partners and their focus countries

\begin{tabular}{|l|l|}
\hline Responsible consortium partner & Focus group: Countries \\
\hline Institut de l'Elevage, France & A: France, Switzerland \\
\hline Altavia Company, Italy & B: Italy, Spain, Portugal, Greece, Cyprus, Malta, Bulgaria \\
\hline Wageningen UR Livestock Research & C: UK, Ireland, Netherlands, Belgium, Luxembourg, \\
\hline KTBL, Germany & D: Germany, Austria \\
\hline MTT Agrifood Research Finland & E: Latvia, Estonia, Lithuania, Sweden, Finland, Denmark \\
\hline WirelessInfo, Czech Republic & F: Poland, Czech, Slovenia, Slovakia, Hungary, Romania \\
\hline
\end{tabular}

The research has focused on farmers in connection with internal (on-farm) and external (business-chain) processes. For the research, semi-structured questioning, followed by telephone interviews were used in this study. The semi-structured template for the questionnaire was developed based on the framework (Figure 1) by Giachetti (2004) to facilitate enquiring and analyzing information on network and integration between enterprises. The investigation employed experts for a quantitative and qualitative inquire. The experts located in each country provided information about agricultural data exchange in their respective countries. For each country separate reports were prepared. Finland was responsible for conducting the research in the Nordic and Baltic States. In the analysis of the results, the framework by Giachetti (2004) was used to "map" the current state of system and information integration in the research countries. 


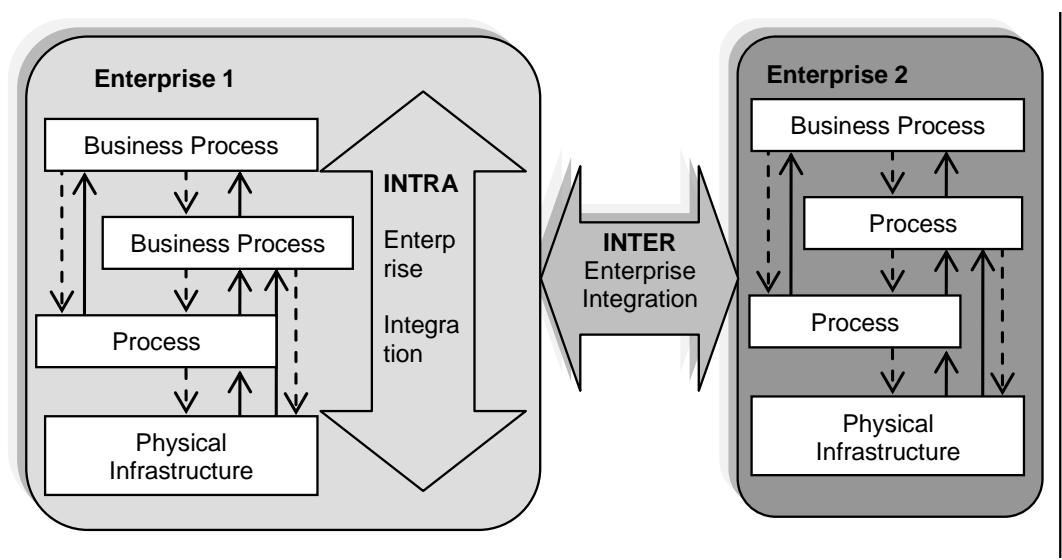

Figure 1. Generic Integration Framework (adapted from Giachetti, 2004)

The mapping covered processes, applications, data, and physical infrastructure in agricultural data exchange with particular reference to characteristics of farms, the level of automation, data integration, ICT and technology usage. A summary of the key results are given in the next section.

\section{Results and discussions}

Trends in farm characteristics: According the results of the research, arable farms are largest in the Czech Republic, Denmark, UK and France. In Bulgaria, Romania, Slovakia and Hungary more than $50 \%$ of the arable holdings have land areas of less than 2 ha. The largest dairy farms were in Denmark, Cyprus, Czech Republic and the UK. In Romania, Bulgaria, Lithuania, Slovakia, Latvia, Poland, Estonia and Hungary, more than $80 \%$ of the dairy holdings have less than 10 cows.

Farm automation level: By characterizing precision farming (PF) as a measure of farm automation, in most EU countries, PF is only used to a small extent by farmers. A lot of experts reported the existence of $\mathrm{PF}$ and the usage of Geo spatial data only in experimental (research) projects. However, there is a significant difference in areas across Europe, in Western and North Europe and for example in Czech Republic there is more progress in PF development. Manufacturers of agricultural machines are the main booster for adaptation of PF techniques in developed countries such as Germany, the Netherlands, Denmark and Finland.

Data integration: In general big differences all over Europe can be seen in data integration at process level. The availability and accessibility of (broadband) Internet in rural areas is an issue in most countries. Except from some countries like Germany, France, Denmark, Belgium and the Netherlands, no (private) unions or bodies are reported who take care of the organization of dataflow or standardization. Collaboration between private and public organization to advanced infrastructure is also low in countries like Romania, Slovakia, Czech Republic and Lithuania.

In many EU countries data definitions (semantics) have only public standards (XML schema's and web services for example) mentioned. Standards definitions such as ISOBUS are available for example machinery (ISObus), milking equipment (ISO 11788 ADED), electronic animal identification (ISO 11784/11785/14223 and 24631) or forestry (ISO 19115). Syntaxes for EDI messaging from agroXML (Germany, some other countries), ISOagrinet (international), Agro EDI Europe and Edaplos (France), AgroConnect (The Netherlands) were reported. However, data integration along the whole food chain from farm to consumer is still lacking.

ICT and technology usage: Agricultural technology adaptation and developments are not always positive because of lack of young people in agriculture (Slovakia, Bulgaria, Italy, others). Countries having a lot of small (probably poor as well) farmers are facing severe problems in the capabilities of investing in automation. Fast developing agricultural countries like the Baltic States have high potentials concerning the building of new ICT infrastructure as they are not bothered by old systems and structures. Availability of broadband internet in rural areas is very often mentioned as a big issue that hampers ICT adaptation in agriculture. A summary of the level of ICT and technology adaptation in some of the EU countries and Switzerland is presented in Table 2. 
Table 2. Responsible consortium partners and their focus countries

\begin{tabular}{|l|l|l|l|l|l|l|l|l|}
\hline Country & $\begin{array}{c}\text { Farm } \\
\text { PC }\end{array}$ & Internet & $\begin{array}{c}\text { Farm } \\
\text { Info. Sys. }\end{array}$ & $\begin{array}{c}\text { Phones/ } \\
\text { Handheld }\end{array}$ & $\begin{array}{c}\text { LPIS } \\
\text { relevance }\end{array}$ & $\begin{array}{c}\text { Geo } \\
\text { Fertili- } \\
\text { zing }\end{array}$ & $\begin{array}{c}\text { Animal } \\
\text { Registr- } \\
\text { ation }\end{array}$ & $\begin{array}{c}\text { Data Exchange } \\
\text { Level of } \\
\text { Development }\end{array}$ \\
\hline BGR & Low & Low & Low & - & Average & - & - & Hardly any \\
\hline CZE & High & High & High & Low & Average & Average & - & Averagely \\
\hline DNK & High & High & - & High & High & Average & High & Well \\
\hline EST & High & High & Average & - & Average & Low & Average & Poorly \\
\hline FIN & High & High & High & High & High & Average & High & Well \\
\hline FRA & High & Average & Average & High & High & Average & High & Well \\
\hline HUN & Average & Average & Low & Low & Average & Low & Average & Poorly \\
\hline ITA & Average & Low & Average & Average & Average & Average & High & Average \\
\hline LVA & Low & High & Low & - & Average & Low & High & Poorly \\
\hline NLD & High & High & High & High & High & Average & High & Well \\
\hline POL & Average & Average & Average & - & Average & Low & Average & Hardly any \\
\hline ROM & Low & Low & Low & Low & Average & - & Average & Hardly any \\
\hline SVK & High & Average & Low & Low & Average & Low & Average & Poorly \\
\hline SVN & Low & Low & Low & Low & Average & - & Average & Poorly \\
\hline ESP & High & - & Average & Low & High & Low & High & Averagely \\
\hline SWE & High & - & - & High & High & Low & High & \\
\hline CHE & High & Average & Average & Low & Average & Low & High & Averagely \\
\hline
\end{tabular}

\section{Conclusions}

Based on the analysis of the state of the art in the present report, the challenges for future research and development of data exchange in the European agriculture were identified. Aging population of farmers which manifests itself through the lack of adaption and investments in new technology, especially in Southern and Eastern countries was noted. Lack of broadband availability in rural areas was reported. Furthermore, mobile infrastructures in most countries are not capable of sustaining the potential of use of mobile computing base for data communications which needed in emerging technologies for farm production. There is potential for countries that are developing quickly to adapt new data exchange infrastructural models and skip the complex and inefficient structures that currently exist in some EU countries. There are substantial differences across the EU in relation to the level of data integration and standardization ranging from none or hardly any data integration to quite well developed (France, Germany, The Netherlands and Denmark).

As a recommendation, it is that open networks with flexible relationships between network partners will facilitate successful integration of the systems. Technology service providers and users need to be convinced about the benefits. Finally, focus should on putting research information into practice to demonstrate data harmonization processes, however, this should be kept flexible and hence keep the rigidity of (formal) standardization processes minimal in agricultural data harmonization.

\section{Acknowledgements}

The agriXchange project is funded by the EU within the FP7 programme for KBBE (Knowledge-Based Bio Economy). The focus group (Table 1) and respective country experts who contributed to the information reproduced in this paper are acknowledged. More information can be found at http://www.agrixchange.org.

\section{References}

Technology Platform 'Organics'. 2010. European Strategy and Action plan towards a sustainable bio-based economy by 2020. http://www.tporganics.eu/upload/TPOrganics_ImplementationActionPlan.pdf.

Nikkilä, R., Seilonenen, I, and Koskinenen, K. 2010. Software Architecture for Farm Management Information Systems in Precision Agriculture. In: Computers and Electronics in Agriculture 70 (2): 328-336.

Sørensen, C., Fountas, S., Nash, E., Pesonen, L., Bochtis, D., Pedersen, S., Basso, B. \& Blackmore, S. 2010. Conceptual Model of a Future Farm Management Information System. In: Computers and Electronics in Agriculture 72: 37-47.

Gebbers, R. \& Adamchuk, V. 2010. Precision Agriculture and Food Security. Science 327: 828-831.

GCI.,2006. 2016: The Future Value Chain. Global Commerce Initiative, Capgemini \& Intel Publication. 45p.

Giachetti, E. 2004. A framework to review the information integration of the enterprise. International Journal of Production Research 42: 1147-1166. 